\title{
$\angle S$ Research Soure \\ Preparation of Aspergillus niger 426 naringinases for debittering citrus juice using of agro-industrial residues
}

\section{Fernanda de Oliveira}

Universidade Estadual de Londrina

Tereza Cristina Luque Castellane ( $\nabla$ terezacastellane@gmail.com )

Universidade Estadual Paulista: Universidade Estadual Paulista Julio de Mesquita Filho https://orcid.org/0000-0002-7290-5314

Marcelo Rodrigues de Melo

Universidade Estadual Paulista

João Batista Buzato

Universidade Estadual Paulista

\section{Research Article}

Keywords: Agro-industrial residues, Aspergillus niger, Experimental Mixture Design, Solid-state fermentation

Posted Date: April 22nd, 2021

DOI: https://doi.org/10.21203/rs.3.rs-356289/v1

License: (c) (1) This work is licensed under a Creative Commons Attribution 4.0 International License. Read Full License

Version of Record: A version of this preprint was published at International Microbiology on August 7th, 2021. See the published version at https://doi.org/10.1007/s10123-021-00199-5. 


\section{Abstract}

Naringin (4,5,7-trihydroxy flavanone-7-rhamnoglucoside), considered as the main bitter component of grapefruit, requires the use of enzymes to reduce the level of this substance during juice processing. For this reason, it has been the focus of many studies. To increase the production of naringinase by Aspergillus niger cultivated in solid-state fermentation (SSF), it was verified whether the influence of agroindustrial residues as fermentation substrates and, finally, selected the best of the three inducers, or their mixtures to remove the bitterness of grapefruit juice. Cultivation with $2.3 \mathrm{~g}$ of grapefruit peel, $2.5 \mathrm{~g}$ of rice bran, and $5.2 \mathrm{~g}$ of wheat bran and medium supplementation with a mixture of naringin, rutin, and hesperidin in the concentration of $(\mathrm{g} / \mathrm{L}): 2,5,4.5$, and 3.0, respectively, leading to a maximum activity of $28 \mathrm{U} / \mathrm{mL}$. The results indicate that the sequencing procedure, which allowed the definition of an optimal mixture of components, is a new way for microorganisms to have a high naringinase yield, in particular by SSF, since our data showed a $96 \%$ increase in the production of naringinase.

\section{Introduction}

Naringin (4,5,7-trihydroxy flavanone-7-rhamnoglucoside) is the major flavanone in grapefruit and it is responsible for bitter taste. The presence of bitterness, generally, has been the major limitation for the commercial acceptance of juices [1]. For this reason, naringinase (EC 3.2.1.40) has attracted increasing research attention due to its broad range of positive enzymatic hydrolysis is a possibility to overcome the bitterness and obtain compounds with improved biological activities.

Naringinase is a hydrolytic enzyme that contains the activities a-L-ramnosidase (E. C. 3.2.1.2.3) and betaglucosidase (EC 3.2.1.21). In the first stage of hydrolysis, the hydrolysis catalysis of naringin $(4,5,7-$ trihydroxy flavanone 7-ramnoglucoside) occurs, in rhamnose and prunin. Being that, the prunin who is responsible for one third of the bitterness of the naringin. Second phase, prunin is hydrolyzed to tasteless naringenin (4,5,7-trihydroxy flavanone) and glucose [2,3]. In the other stage, the enzyme $\beta$-glucosidase converts glucose from prunin and naringenin (4,5,7-trihydroxy flavanone) when releasing a D-glucose molecule [4]. There are many substrates like naringin, rutin, quercitrin, hesperidin, diosmin, and ter-phenyl glycosides, containing terminal a-rhamnose and $\beta$-glucose [5]. These products are the basic material for the synthesis of many substances.

It is commercially attractive due to its potential utility in citrus juices debittering, especially in grapefruits, and wine industries, reducing the intensity of its bitter taste. Naringinase, an important enzyme complex, also finds applications in the field of biotechnology, pharmaceuticals, and other industries, such as biotransformation steroids, antibiotics, and mainly glycolide hydrolysis, glycopeptides, flavonoid deglycosylation, and gelane depolymerization [6, 7]. Additionally, due to its medicinal properties, for example, improved signaling via, anti-inflammatory, anticancer also has great commercial importance in the medical area [8]. 
New screening methods for the potential production of naringinase by microorganisms have been described [9]. Naringinase can be obtained by fermenting various microorganisms, including especially Aspergillus oryzae 11250 [10], Rhizophus stolonifer [11], Trichoderma longibrachiatum ATCC18648 [12], among others. However, the fungus species $A$. niger is the preferred source of a variety of enzymes or expression system for foreign proteins. This species, several of which have a long history of safe use in the fermentation industry, is one of the most important sources of naringinase industrial use, such as for food industrial use mainly due to its safety characteristics and viable culture processes [13].

Several publications describe the improvement in naringinase production. For example, using an inductor [11], the presence of citrus peel, a source of naringin [2], or the optimization of the concentration of the substrates, carbon source or nitrogen sources [14] and temperature [15].

The industrial application of enzymes is growing exponentially, together with its wide application, it is necessary to increase the production of naringinase. In this case, optimizing the culture conditions, especially by adding enzyme inducers. This work aimed to define the concentration of three agroindustrial residues, among them grapefruit rind as a specific inducer, and three known inducers of naringinase (naringin, rutin, and hesperidin) by Experimental Mixture Design (EMD) using solid-state fermentation (SSF). This methodology is attractive because it can be applied to study the proportion of the components in a given culture medium, and can aid with the identification of relationships amongst these components during naringinase production.

\section{Materials And Methods}

\subsection{Materials}

Orange rind, grapefruit rind, rice bran, and wheat bran were used as solid substrates. The residues were provided by local agroindustry, then dried to $2 \%(\mathrm{w} / \mathrm{w})$ humidity in an oven at $70^{\circ} \mathrm{C}$ for $24 \mathrm{~h}$ and milled in a mill Wiley type at a particle size of approximately $2 \mathrm{~mm}$.

Naringin, rutin, hesperidin, quercetin, citric acid, glucose, sucrose, xylose, and raffinose were purchased from Sigma-Aldrich (St. Louis, MO). HPLC-grade methanol and acetonitrile were products from Tedia Co. Inc. (Fairfield, $\mathrm{OH}$ ). All other reagents were from analytical grade.

\subsection{Microorganism}

Aspergillus niger strain 426 was isolated from dried prunes and identified by the Institute of Food Technology (UNICAMP, Brazil). Stock cultures were stored at $4{ }^{\circ} \mathrm{C}$ on potato dextrose agar (PDA) slants. Microorganism activation was carried out in PDA plates at $28^{\circ} \mathrm{C}$ for 3 days. The inoculum was prepared by harvesting the spores from 3-day-old cultures by adding $0.1 \%(\mathrm{v} / \mathrm{v})$ Tween-80, and diluted to the desired spore concentration $\left(1 \times 10^{9} \mathrm{spores} / \mathrm{g}\right.$ substrate). The pour plate technique was used to calculate the number of spores. 


\subsection{Fermentation conditions}

All cultivations were carried out in 250-mL Erlenmeyer flasks at a fixed total of $10 \mathrm{~g}$ of dry substrate. The substrate was moistened with a nutrient solution containing the following ingredients $(\mathrm{g} / \mathrm{L}):\left(\mathrm{NH}_{4}\right) \mathrm{H}_{2} \mathrm{PO}_{4}$ (5.0), $\mathrm{K}_{2} \mathrm{HPO}_{4}$ (1.5), $\mathrm{MgSO}_{4} .7 \mathrm{H}_{2} \mathrm{O}(0.5), \mathrm{KCl}$ (0.5), yeast extract (5.0), and inducer (10.0). The pH was adjusted to 4.5 before sterilization. A volume equal to $10 \%(\mathrm{v} / \mathrm{v})$ of inoculum was transferred to previously sterilized Erlenmeyer flasks containing $10 \mathrm{~mL}$ of nutrient solution with different components under investigation (orange rind, grapefruit rind, rice bran, and wheat bran) and incubated for 5 days at 28 ${ }^{\circ} \mathrm{C}$ with $97 \%(\mathrm{v} / \mathrm{v})$ controlled atmospheric humidity. The moisture content was adjusted to $75 \%(\mathrm{v} / \mathrm{v})$ by the addition of distilled water into the 250-mL Erlenmeyer flasks. With the fermentation flasks placed in an iced bath, the cell-free enzymatic extracts were recovered by adding $5 \mathrm{~mL}$ of sodium acetate buffer 50 $\mathrm{mM}, \mathrm{pH} 4$ and further mixing using a glass rod. Subsequently, the suspension was filtered and centrifuged $9000 \mathrm{~g}$ for $15 \mathrm{~min}$ at $4{ }^{\circ} \mathrm{C}$ and the clear, brown supernatant was used for subsequent analysis.

\subsection{Substrate and inducer selection for naringinase production}

In a first step, cultures were carried out in a 250-mL Erlenmeyer flask with $10 \mathrm{~g}$ of orange or grapefruit rind moistened with nutrient solution, but without the addition of inducers, to evaluate, between these two inducer substrates, which one was the best for naringinase production.

It was set up two EMD as a simplex centroid design (Table 1), with $2^{q-1}$ combinations of mixtures, where $q$, the number of components or variables whose sum is 1 or $100 \%$, to 3 components. First, grapefruit rind, rice bran, and wheat bran were used for substrate selection for naringinase production (EMD 1). Because the mixture space is a simplex, all design points must be at the vertices, on the edges or faces, or in the interior of a simplex [16]. Thus, runs with a single substrate, called linear blending (100\%), $10 \mathrm{~g}$ of grapefruit rind, $10 \mathrm{~g}$ of rice bran, and $10 \mathrm{~g}$ of wheat bran was used. A special cubic model was used to represent the mean of the response variable as a function of the factors described in Equation 1: see

\section{equation 1 in the supplementary files.}

where $Y$ is the naringinase activity $(\mathrm{U} / \mathrm{mL}), y$ the estimated parameters, and $x_{i}$ is the level of the independent variable. The statistical significance of the regression coefficients was determined by Fischer's test for analysis of variance (ANOVA) at a significance level of $p \leq 0.05$, and the extent of variance explained by each model was given by the determination coefficient $R^{2}$. To minimize the error of ANOVA, the tests corresponding to the central point were repeated three times. Experimental and predicted values were compared to determine the validity of the models. The best mixture of substrates was used to study the ideal concentration of inducers naringin, rutin, and hesperidin from 5 to $25 \mathrm{~g} / \mathrm{L}$ added in a nutrient solution.

In a second step, EMD 2 was also set up as a simplex centroid design (Table 1) and the components studied were naringin, rutin, and hesperidin at a fixed total concentration of $10 \mathrm{~g} / \mathrm{L}$. Control of each 
condition was conducted without the addition of spores to the nutrient solution for the subsequent quantification of residual inducers. The remaining culture solution components were always the same, and the culture conditions were as described above. All the EMD design and analysis were performed using STATISTICA 7.0 software [17].

\subsection{Naringinase Activity}

The modified method of Thammawat et al. [18] was followed to assess naringinase activity. $1 \mathrm{~mL}$ of enzyme extract was added to $1 \mathrm{~mL}$ of $1 \%(\mathrm{w} / \mathrm{v})$ naringin in an acetate buffer $0.1 \mathrm{M}(\mathrm{pH} 4.0)$. After incubation at $50{ }^{\circ} \mathrm{C}$ for $60 \mathrm{~min}, 0.1 \mathrm{~mL}$ was withdrawn. To this solution, $3.0 \mathrm{~mL}$ of diethylene glycol $(90 \%$, $\mathrm{v} / \mathrm{v})$ and $0.1 \mathrm{~mL}$ of $(4.0 \mathrm{~N}) \mathrm{NaOH}$ were added and incubated for $10 \mathrm{~min}$ at room temperature. The intensity of the yellow color produced was measured at $420 \mathrm{~nm}$. One unit of naringinase activity is defined as the amount of enzyme that is required to hydrolyze $1 \mu \mathrm{mol}$ of naringin per $\mathrm{ml}$ per minute, under the assay conditions.

\subsection{Quantification of sugars}

The extraction of soluble sugars from defatted substrates was performed according to the methodology proposed by Saravitz et al. [19] and filtrated through $0.45 \mu \mathrm{m}$ filter (Millipore). When finished, the filtrate collects in the attached $1 \mathrm{~mL}$ Eppendorf tube. For the analysis of sugars, aliquots of $20 \mu \mathrm{L}$ extracted samples were injected to HPLC (Model: Hitachi L-5000) using an Aminex HPX-87P column (300 $x 7.8 \mathrm{~mm})$ and eluted in a mobile phase of acetonitrile: water $(75: 25, \mathrm{v} / \mathrm{v})$ in the following chromatographic conditions: $35^{\circ} \mathrm{C}$ injection temperature, a flow rate of $1 \mathrm{~mL} / \mathrm{min}$ in an HPLC system equipped with a RID detector (Shimadzu model RID - 10A). Each analysis was performed in triplicate. The total sugar level in each culture was determined using the phenol-sulfuric method described by Dubois et al. [20].

\subsection{Quantification of citric acid from grapefruit rind}

After extraction of soluble sugars from grapefruit rind, the material was resuspended in $500 \mu \mathrm{L}$ of methanol. Citric acid was analyzed by reversed-phase chromatography (RP-HPLC) system equipped with a model SPD-M10A VP photodiode-array (PDA) detector (Shimadzu Scientific Instruments, Kyoto, Japan). The culture supernatant was filtered through $0.22 \mu \mathrm{m}$ nylon filter. Citric acid was separated using RP-18 column. The mobile phase consisted of $0.1 \%(\mathrm{w} / \mathrm{v})$ phosphoric acid with a flow rate of $1 \mathrm{~mL} / \mathrm{min}$. The detection was at $210 \mathrm{~nm}$. It was identified and quantitated by comparing the retention time and peak area with solutions of pure citric acid.

\subsection{Quantification of flavonoids}

An aliquot $(2 \mathrm{~mL})$ of fermentation extracts was filtered through $0.45 \mu \mathrm{m}$ Teflon membranes. Before the injection into the chromatographer column, $400 \mu \mathrm{L}$ of the samples were added to $600 \mu \mathrm{L}$ of methanol. An HPLC (Model: Hitachi L-5000) coupled with a Symmetry $\mathrm{C}_{18}$ reverse-phase column (bonded $\mathrm{C}_{18}$ ligands 
on a high-purity base-deactivated silica) $(4.6 \times 150 \mathrm{~mm}, 3.5 \mu \mathrm{m})$ and a 2487 UV detector (Waters Corp., Milford, MA) was used to determine the concentrations of residual flavonoids. Following an injection of $20 \mu \mathrm{L}$ of the reaction mixture, the column was eluted using a gradient elution at $35^{\circ} \mathrm{C}$ and $0.4 \mathrm{~mL} / \mathrm{min}$. The mobile phase was composed of $11.4 \%$ methanol, $22.4 \%$ acetonitrile, and $62 \%$ purified deionized water. The target compounds were captured by a 2487 UV detector at $280 \mathrm{~nm}$. The same methodology was used to quantify flavonoids impregnated in defatted grapefruit rind resuspended in $500 \mu \mathrm{L}$ of methanol.

\section{Results And Discussion}

In previous shake-flasks experiments with $A$. niger 426 at $28^{\circ} \mathrm{C}$ and $\mathrm{pH} 4.5$, which were conducted on 10 $\mathrm{g}$ of orange or grapefruit rind added to a nutrient solution but without any addition of inducer, naringinase production was observed on both substrates. Maximal enzyme production was observed on grapefruit rind $(1.92 \pm 0.23 \mathrm{U} / \mathrm{mL})$ against $1.05 \pm 0.26 \mathrm{U} / \mathrm{mL}$ of activity when orange rind was tested. These results were supported by Mendoza-Cal et al. [21] who also yielded higher amounts of naringinase using grapefruit rind instead of orange rind as substrate. Puri et al. [2] reported that citrus peel powder contains high proportions of polyphenols, which act as inducers on narigninase production. The increased production of naringinase with $A$. niger on grapefruit rind is probably due to its very high naringin content and very low content of naringinase inhibitor compounds, such as monosaccharides when compared with orange rind $[6,22]$. When the levels of monosaccharides decrease, naringinase synthesis is induced by naringin, leading to an increased naringinase production. This induction mechanism may help $A$. niger to degrade naringin to access further other nutrient supplies in the media, especially carbon [23]. Because of its high level of flavonoids, grapefruit rind was selected as one of the substrates for more in-depth studies of naringinase production. This is advantageous from an industrial point of view because naringinase can be produced cheaply by using agricultural waste.

\subsection{Effect of substrate on naringinase production}

The effect of the inclusion of naringin $(10 \mathrm{~g} / \mathrm{L})$ was investigated. Since the variation in $\mathrm{pH}$ and temperature of the initial medium can have significant effects on the growth and production of naringinase by species of different fungi, including Aspergillus, we chose the acid pH 4.5, below or higher than this $\mathrm{pH}$ range, which can result in a drastic reduction in naringinase activity. Since the molecular charges and consequently the molecular interactions and functions are directly related to the $\mathrm{pH}$ of the medium; so any change in average $\mathrm{pH}$ affects many biological functions. Therefore, at $28^{\circ} \mathrm{C}$ and $\mathrm{pH} 4.5$, the time of 24 and 120 hours of SSF by $A$. niger showed greater production of naringinase, $22.4 \pm 0.73 \mathrm{U}$ $/ \mathrm{mL}$, respectively (Fig. 1). The central point was composed of a ternary mixture of $33.33 \%$ of each support substrate (grapefruit peel, rice bran, and wheat bran). After $120 \mathrm{~h}, 97 \%$ of the carbon source coinsured in $5 \mathrm{~mL}$ of fermentation extract had been consumed and the enzyme formation was reduced. In this way, all of the following crops were carried out for only 5 days. 
Table 1 summarizes the different combinations of grapefruit peel, rice bran, and wheat bran used for $A$. niger crops, and the maximum activities, in terms of naringinase for EMD 1. The maximum values of naringinase obtained in the experiments varied from 1.6 (run 1) to $22.6 \mathrm{U} / \mathrm{mL}$ (run 7), (Table 1).

The special cubic model was determined to estimate naringinase titers in terms of the concentrations of the components grapefruit rind $\left(x_{1}\right)$, rice bran $\left(x_{2}\right)$, and wheat bran $\left(x_{3}\right)$ in the cultivation medium, as described by Eq. (2), in which terms with an asterisk are significant $(p<0.05)$. See equation 2 in the supplementary files.

A preliminary analysis of this data revealed the significance of the agro-industrial residues used as substrates for naringinase production. All linear blendings showed a statistically significant positive influence on naringinase activity titers since $p$-values were smaller than 0.05 for each of the components. As linear blending, wheat bran was significant in the highest level; which means that an increase of this substrate in the culture medium could improve the results. However, the quadratic term $x_{1} x_{2}$ (grapefruit rind and rice bran) was not significant, with $p>0.05$. The most significant effect on naringinase activity was composed of a ternary mixture of each supporting substrate $\left(x_{1} x_{2} x_{3}\right)$, followed by the quadratic term $\left(x_{1} x_{3}\right)$. The determination coefficient for naringinase production was $99.96 \%$ for EMD 1. According to Silva et al. [24] values of $\mathrm{R}^{2}>90 \%$ are very good in the experimental design of bioprocesses.

Since the least favorable condition was grapefruit rind as a sole substrate $(1.6 \mathrm{U} / \mathrm{mL}$, Table 1$)$ and due to the presence of citric acid in grapefruit juice, it was decided to study the effect of citric acid and sugars on naringinase activity. Norouzian et al. [25] reported that citric acid at $0.02 \mathrm{M}$ non-competitively inhibited naringinase activity. Repression of naringinase activity by glucose and sucrose was also reported by Puri et al. [6], although these carbon sources supported excellent growth.

A quantitative HPLC analysis of substrates sugars found that grapefruit rind presented high amounts of glucose and sucrose ( 625.299 and $4.273 \mathrm{mg} / \mathrm{g}$ of dry substrate, respectively), (Table 2). Unlike wheat bran that presented the lowest amount of glucose $(12.2 \mathrm{mg} / \mathrm{g}$ of the dry substrate). The number of sugars present in grapefruit rind might suggest a change in the metabolism of $A$. niger and a subsequent decrease in naringinase activity, this might also be due to citric acid amount $305.55 \pm 0.172 \mathrm{mg} / \mathrm{g}$ of dry substrate, which represents $1.59 \mathrm{M}$ present in $10 \mathrm{~g}$ of grapefruit rind, and could cause inhibition of naringinase biosynthesis. Although, grapefruit rind has a high content of naringin and rutin, $8.884 \pm 0.464$ and $5.503 \pm 0.65 \mathrm{mg} / \mathrm{g}$ of dry substrate, respectively, which act as flavonoids inducers for naringinase production, so it can't be discarded as a substrate in the mixture.

The models used to describe the effects of each component on naringinase production (Eq. (2)) were used to generate the contour plots shown in Fig. 2a. These results revealed a broad region of elevated naringinase production. Using our data, a predictive analysis estimated the maximum naringinase activity to be $23.94 \mathrm{U} / \mathrm{mL}$ in cultures that contained $2.3 \mathrm{~g}$ of grapefruit rind, $2.5 \mathrm{~g}$ of rice bran, and $5.2 \mathrm{~g}$ of 
wheat bran. Additional cultivation was performed to validate the proposed model and yielded a mean naringinase activity of $23.2 \pm 0.02 \mathrm{U} / \mathrm{mL}$. This result corresponded to $97 \%$ of the expected value, validating the effectiveness of the predictive model and confirming the substrate's proportions.

\subsection{Comparison of different inducers on naringinase production}

For a variety of applications, to increase the production of naringinase, an inducible enzyme, optimize the culture conditions, especially by performing the continuous or gradual addition of a type of inducer [26]. For the production of naringinase, the inducers reported are generally natural substrates or substrate analogs for the enzyme, such as naringin [6, 27], rutin [28] and hesperidin [29].

To evaluate the effect of flavonoid concentration on the production of naringinase by $A$. niger, the addition of naringin, rutin, and hesperidin in various concentrations was performed based on the bestselected condition of the EMD 1 culture. Naringinase activity was observed in all media (Fig. 3), maximum naringinase was produced with rutin $(27.48 \pm 1.23 \mathrm{U} / \mathrm{mL})$ followed by naringin $(23.45 \pm 0.96$ $\mathrm{U} / \mathrm{mL})$ and hesperidin $(23.22 \pm 1.12 \mathrm{U} / \mathrm{mL})$ at a concentration of $10 \mathrm{~g} / \mathrm{L}$. The increase in the concentration of the inducers had no significant effect on the production of the enzyme. Custodio et al. [30] also reported that rutin $(0.5 \%, \mathrm{w} / \mathrm{v})$ was considered the most effective inducer of a-L-ramnosidase production among quercitrin, naringin, naringenin, hesperetin, and hesperidin. On the other hand, Kumar et al. [28] reported a naringinase activity in different five media, that the enzyme naringinase had maximum production in naringin $(7.48 \mathrm{IU} / \mathrm{ml})$ while rutin $(3.71 \mathrm{lU} / \mathrm{ml})$. It is also worth mentioning that our products obtained in this work were much higher than the findings by Kumar et al. [28]. These same authors observed that with rutin and naringenin, naringinase was produced on the 8th day, but the enzyme activities were not distinguished on the 11th day.

To improve naringinase yield using citrus residues, Borkar et al. [15] studying the fermentative production

of naringinase from A. niger van Tieghem MTCC 2425 with an inducer concentration of $14.9 \mathrm{~g} \mathrm{~L}^{-1}$ verified an ideal naringinase activity of $545.2 \mathrm{IU} \mathrm{g}^{-1}$ and concluded that the $\mathrm{pH}$ and the medium temperature act synergistically for the production of the enzyme, while the antagonistic behavior of the temperature and the concentration of the inducer at higher levels leads to a decrease in enzyme activity [15]. On the other hand, they obtained the activity of the enzyme can be completely reserved for up to 5 months at $4{ }^{\circ} \mathrm{C}$, same in the literature, naringinase from this species favored $45^{\circ} \mathrm{C}$ for naringinase activity [3]. However, researchers noted that scaling parameters vary significantly about microbial types, such as bacteria or fungi. About the fungus Aspergillus niger, studies that identify the most influential factors among the different media and process parameters during fermentation to produce naringinase are still scarce.

\subsection{Effect of a mixture of inducers}

To select the best mixture of inducers, fermentation experiments were performed based on the best condition selected from EMD 1 cultivation using $10 \mathrm{~g} / \mathrm{L}$ of inducers concentration (Table 1, EMD 2). Maximum naringinase activities can be found in the central points that are composed of a ternary mixture of each inducer. According to the analysis of variance (ANOVA), the regression was statistically 
significant $(p<0.05)$. The high value of the coefficient of determination $\left(R^{2}=0.994\right)$ indicates that $99.4 \%$ of the variability of the responses can be explained by the model. The value of the adjusted determination coefficient (adjusted $R^{2}=0.977$ ) is also high, showing a high significance of the model.

In this way, the mathematical model representing naringinase production by adding inducers naringin $\left(\mathrm{x}_{1}\right)$, rutin $\left(\mathrm{x}_{2}\right)$ and hesperidin $\left(\mathrm{x}_{3}\right)$ in the experimental region considered here can be expressed as: see equation 3 in the supplementary files.

Similar to Eq. (2), Eq. (3) indicated that the most significant effect on naringinase activity was composed of a ternary mixture of each inducer, resulting in a naringinase activity of $28.16 \mathrm{U} / \mathrm{mL}$ (Table 1). Because $x_{2}>x_{3}>x_{1}$ we would conclude that rutin $\left(x_{2}\right)$ increases naringinase production. Although all the linear terms, as well as the cubic term, had significant effects on the maximum attainable value of naringinase production, it can be seen that the effect of the quadratic term was not significant $(p>0.05)$. Furthermore, because $x_{2} x_{3}$ is negative, blending rutin and hesperidin would have an antagonistic effect, which means that the proportion of rutin in the blending should be greater than hesperidin. These results can provide a reference for inducer selection for similar studies in the future. To our knowledge, this is the first time that a mixture of inducers combined with the analysis of responses by Response Surface Methodology and optimization through a desirability function is used for producing naringinase.

According to Bokkenheurser et al. [31], rutin can be hydrolyzed to the monosaccharide 3glucosylquercetin, which could be further hydrolyzed to the aglycone, quercetin by the $\beta$-D-glucosidase portion of naringinase.

A quantitative HPLC analysis of the fermentation broth revealed the presence of the inducer rutin in Controls 4-7, which represents cultivations without inoculation, and its aglycone quercetin in Runs 4-7 of the EMD 2 (Table 3). This indicates that A. niger successfully metabolized rutin. Additionally, rutin was detected at a concentration of $2.435 \pm 0.422 \mathrm{mg} / \mathrm{mL}$ in Control 5 of EMD 2 even though it was not added. A possible explanation could be that rutin is coming from grapefruit rind, which has a rutin concentration of $5.503 \pm 0.65 \mathrm{mg} / \mathrm{g}$ of the dry substrate (Table 2). This highlights the importance of agroindustrial residues application since this reduces the costs of production by the addition of flavonoids. This is advantageous on two levels, first because grapefruit rind is an inexpensive carbon source compared to other carbon sources and second its application on naringinase production could solve environmental problems resulting from grapefruit waste.

For better industry usage of this waste, it could be done a pre-treatment for monosaccharides inhibitor removal, but costs have to be taken into account so the process would remain financially advantageous.

The graph of the response surface (Fig. 2b) showed that maximum naringinase production could be achieved with a mixture of naringin, rutin, and hesperidin at a concentration of $2.5,4.5,3.0 \mathrm{~g} / \mathrm{L}$, respectively; furthermore, the inducer rutin would increase enzyme activity. The maximum predicted value was $27.86 \mathrm{U} / \mathrm{mL}$. The mean value of the experimental validation of the optimized condition $(28.10 \pm 0.45$ 
$\mathrm{U} / \mathrm{mL}$ ) was in excellent correlation with the predicted value, confirming the validity of the model. This activity is comparatively higher than those obtained by Petri et al. [32]. After medium optimization, these authors found a final a-L-rhamnosidase activity of $3.02 \mathrm{U} / \mathrm{mL}$ contained in $5 \mathrm{~mL}$ of enzymatic extract from SSF by A. niger 426 .

\section{Conclusions}

In this work, the first agro-industrial waste was added to a standard medium for SSF, and the best result of the mixture of substrates was used in the second stage of the process. According to a statistical mixing project, the ternary mixture of each solid substrate (grapefruit peel, rice bran, and wheat bran) was also combined with a ternary mixture of inductors (naringin, rutin, and hesperidin) obtained better activity values of naringinase. This sequential procedure allowed the definition of an optimal mixture of components resulting in a $96 \%$ increase in the production of naringinase concerning the orange peel as a tested substrate without the addition of inductors. The results suggest that the proportion of these components can be applied for further investigation, as a lower-cost alternative, adding economic value to waste and by-products and, on the other hand, solving the problem of its disposal, in the production of enzymes, specifically naringenase. Although the grapefruit peel decreases the production of naringinase, it cannot be discarded as a carbon source, due to the large number of flavonoids impregnated in this substrate.

\section{Declarations}

\section{Acknowledgments}

The authors would like to extend their sincere appreciation to the UEL and UNESP for their support and CAPES for funding this work and scholarships.

\section{Author information}

Department of Biochemistry and Biotechnology, State University of Londrina, 86051-980, Londrina, Paraná, Brazil.

Fernanda de Oliveira, Marcelo Rodrigues de Melo and João Batista Buzato.

Departamento de Tecnologia, UNESP - Univ Estadual Paulista, Faculdade de Ciências Agrárias e Veterinárias, Rod. Prof. Paulo Donato Castellane km 5, CEP 14884-900, Jaboticabal, SP, Brasil.

Tereza Cristina Luque Castellane

\section{Authors' Contributions}

Fernanda de Oliveira: research conceptualization, data curation, investigation and methodology, writing; Tereza Cristina Luque Castellane: HPLC investigation and methodology, critically revised the manuscript; 
Marcelo Rodrigues de Melo and João Batista Buzato: research conceptualization and supervison.

\section{Corresponding authors}

Correspondence to Tereza Cristina Luque Castellane and Fernanda de Oliveira.

\section{Funding Information}

The authors would like to extend their sincere appreciation to the CAPES for funding this work.

\section{Ethics declarations}

Conflict of interest

Fernanda de Oliveira, Tereza Cristina Luque Castellane, Marcelo Rodrigues de Melo, and João Batista Buzato declare that they have no conflict of interest.

\section{References}

1. Yusof, S., Ghazali, H.M., King, G.S. (1990) Naringin content in local citrus fruits. Food Chem. 37:11321.

2. Puri, M., Kaur, A., Barrow, C.J., Singh, R.S. (2011) Citrus peel influences the production of an extracellular naringinase by Staphylococcus xylosus MAK 2. App Microbiol Biotechnol. 89:715-722.

3. Puri, M., Banerjee, U. (2000) Production, purification, and characterization of the debittering enzyme naringinase. Biotech Adv. 3:207- 217.

4. Awad, G.E.A., Abd El Aty, A.A., Shehata, A.N., Hassan, M.E., Elnashar, M.M. (2016) Covalent immobilization of microbial naringinase using novel thermally stable biopolymer for hydrolysis of naringin. Biotech. 6:14. doi: 10.1007/s13205-015-0338-x.

5. Ribeiro, M.H. (2011) Naringinases: occurrence, characteristics, and applications. Appl Microbiol Biotechnol. 90(6):1883-95. doi: 10.1007/s00253-011-3176-8.

6. Puri M, Banerjee A, Banerjee UC. Optimization of process parameters for the production of naringinase by Aspergillus niger MTCC 1344. Proc Biochem 2005;40:195-201.

7. Kamiya, S., Esaki, S., Tanaka, R. (1985) Synthesis of some disaccharides containing an L rhamnopyranosyl or L-mannopyranosyl residue, and the substrate specificity of alpha-Lrhamnosidase from Aspergillus niger. Agricul Biol Chem. 49:55-62.

8. Zhang, L., Xu, X., Jiang, T., Wu, K., Ding, C., Liu, Z., Zhang, X., Yu, T., and Song, C. (2018) Oxid. Med. Cell Longev. 1-16.

9. Patil, S. V., Koli, S. H., Mohite, B. V., Patil, R. P., Patil, R. R., Borase, H. P., \& Patil, V. S. (2019). A novel screening method for potential naringinase-producing microorganisms. Biotechnol Appl Biochem. 66(3), 323-327. 
10. Zhu, Y., Jia, H., Xi, M., Li, J., Yang, L., \& Li, X. (2017). Characterization of a naringinase from Aspergillus oryzae 11250 and its application in the debitterization of orange juice. Process Biochem. 62, 114-121. https://doi.org/10.1016/j.procbio.2017.07.012.

11. Karuppaija, S., Kapilan, R., \& Seevaratnam, V. (2016). Optimization of naringinase production by Rhizophus stolonifer in solid state fermentation media using paddy husk as support. Scholars Acad J Biosci. 4(6), 507-514. https://doi.org/10.21276/sajb.2016.4.6.10.

12. Housseiny, M.M., Aboelmagd, H.I. (2019) Nano-encapsulation of naringinase produced by Trichoderma longibrachiatum ATCC18648 on thermally stable biopolymers for citrus juice debittering. J Microbiol. 57(6):521-531. doi: 10.1007/s12275-019-8528-6.

13. Ni, H., Chen, F., Cai, H., Xiao, A., You, Q., Lu, Y. (2012) Characterization and preparation of Aspergillus niger naringinase for debittering citrus juice. J. Food Sci. 77:1-7. doi: 10.1111/j.17503841.2011.02471.x

14. Mukund, P., Belur, P. D., \& Saidutta, M. B. (2013). Production of naringinase from a new soil isolate, Bacillus methylotrophicus: isolation, optimization and scale-up studies. Prep Biochem Biotech. 44(2), 146-163. https://doi.org/10.1080/10826068.2013.797910.

15. Borkar, V., Chakraborty, S., Gokhale, J.S. (2020) Fermentative Production of Naringinase from Aspergillus nigervan Tieghem MTCC 2425 Using Citrus Wastes: Process Optimization, Partial Purification, and Characterization. Appl Biochem Biotechnol. doi: 10.1007/s12010-020-03385-9.

16. Cornell, J.A. Experiments with Mixtures: Designs, Models and the Analysis of Mixture Data. $3^{\text {rd }}$ ed. New York: John Wiley and Sons; 2002.

17. Statsoft, Inc. Statistica (data analysis software system), version 7. 2007. <www.statsoft.com>

18. Thammawat, K., Pongtanya, P., Juntharasri, V., Wongvithoonyaporn, P. (2008) Isolation, preliminary enzyme characterization and optimization of culture parameters for production of naringinase isolated from Aspergillus niger BCC 25166. Nat Sci 42:61-72.

19. Saravitz, D.M., Pharr, D.M., Carter, T.E. (1987) Galactinol synthase activity and soluble sugars in developing seeds of four soybean genotypes. Plant Physiol. 83:185-189.

20. Dubois, M., Gilles, K.A., Hamilton, J.K., Rebers, P.A., Smith, F. (1956) Colorimetric Method for Determination of Sugars and Related Substances. Analytical Chem. 28:350-356.

21. Mendoza-Cal, A., Cuevas, L., Lizama-Uc, G., Ortiz-Vazquez, E. (2010) Naringinase Production from Filamentous Fungi Usign Grapefruit Rind in Solid State Fermentation. African J Microbiol Res. 4:1964-1969.

22. Bram, B., Solomons, G.L. (1965) Production of the enzyme naringinase by Aspergillus niger. Applied Microbiol.13:842-845.

23. Shanmugaprakash, M., Vinoth-Kumar, V., Hemalatha, M., Pothiyappan-Karthik, V.M. (2011) Solid-state fermentation for the production of debittering enzyme naringinase using Aspergillus niger MTCC 1344. Eng Life Sci. 11:322-325. 
24. Silva, C.S., Bovarotti, E., Rodrigues, M.I., Hokka, C.O., Barboza, M. (2009) Evaluation of the effects of the parameters involved in the purification of clavulanic acid from fermentation broth by aqueous two-phase systems. Biopro Biosys Eng. 32:325-632.

25. Norouzian, D., Hosseinzadeh, A., Inanlou, D.N., Moazami, N. (2000) Production and partial purification of naringinase by Penicillium decumbens PTCC 5248. W J Microbiol Biotechnol. 16:471-473.

26. Mateles, R.I., Perlman, D., Humphery, A.E., Deindorfer, F.H. (1965) Fermentation review. Biotechnol Bioen. 7:54-58.

27. Puri, M., Kaur, A., Singh, R.S., Singh, A. (2009) Response surface optimization of medium components for naringinase production from Staphylococcus xylosus MAK2. App Biochem Biotechnol. 162:181-191.

28. Kumar, V.V. (2010) Comparative studies on inducers in the production of naringinase from Aspergillus niger MTCC 1344. African J Biotechnol. 9:7683-7686.

29. Fukumoto, J., Okado, S. (1973) Naringinase production by fermentation. Japanase Patent 7306554.

30. Custodio, M.V.G., Otamendi, F.P., Vidal, D.R., Alventosa, S.V. (1996) Production and characterization of an Aspergillus terreus $\alpha$-L-rhamnosidase of oenological interest. Lebensm Unters Forsch 203:522527.

31. Bokkenheuser, V.D., Shackleton, C.H.L., Winter, J. (1987) Hydrolysis of dietary flavonoid glycosides by strains of intestinal bacteroides from humans. Bioch J. 248:953-956.

32. Petri, A.C., Buzato, J.B., Celligoi, M.A., Borsato, D. (2014) Optimization of the production of a-Lrhamnosidase by Aspergillus niger in solid state fermentation using agro-industrial residues. Brit Microbiol Res J. 4:1198-1210.

\section{Tables}

Table 1. Summary of naringinase maximum values for the A. niger according to EMD, using components grapefruit rind, rice bran, and wheat bran at a total amount of $10 \mathrm{~g}$ for EMD 1, and inducers $(\mathrm{g} / \mathrm{L})$ naringin, rutin and hesperidin at a total concentration of $10 \mathrm{~g} / \mathrm{L}$ for EMD 2. EMD 2 was performed based on the best condition selected from EMD 1. Experiments were run using SSF for 5 days at $28^{\circ} \mathrm{C}$, with initial $\mathrm{pH} 4.5$. 


\begin{tabular}{|c|c|c|c|c|}
\hline $\begin{array}{c}\text { Run } \\
\text { number }\end{array}$ & $\begin{array}{c}\text { Coded } \\
\text { mixture } \\
\left(\mathrm{x}_{1} ; \mathrm{x}_{2} ;\right. \\
\left.\mathrm{x}_{3}\right)^{* *}\end{array}$ & $\begin{array}{c}\text { Original } \\
\text { mixture* } \\
\left(\mathrm{x}_{1} ; \mathrm{x}_{2} ; \mathrm{x}_{3}\right)^{* *}\end{array}$ & $\begin{array}{c}\text { EMD } 1 \text { naringinase } \\
\text { activity } \\
\\
(\mathrm{U} / \mathrm{mL})\end{array}$ & $\begin{array}{c}\text { EMD } 2 \text { naringinase } \\
\text { activity } \\
(\mathrm{U} / \mathrm{mL})\end{array}$ \\
\hline 1 & $(1 ; 0 ; 0)$ & $(10.0 ; 0 ; 0)$ & 1.60 & 23.56 \\
\hline 2 & $(0 ; 1 ; 0)$ & $(0 ; 10.0 ; 0)$ & 17.40 & 25.5 \\
\hline 3 & $(0 ; 0 ; 1)$ & $(0 ; 0 ; 10.0)$ & 18.30 & 26.82 \\
\hline 4 & $(\square ; \square ; 0)$ & $(5.0 ; 5.0 ; 0)$ & 8.70 & 24.56 \\
\hline 5 & $(\square ; 0 ; \square)$ & $(5.0 ; 0 ; 5.0)$ & 20.60 & 25.95 \\
\hline 6 & $(0 ; \square ; \square)$ & $(0 ; 5.0 ; 5.0)$ & 20.10 & 24.89 \\
\hline 7 & $(\square ; \square ; \square)$ & $(3.3 ; 3.3 ; 3.3)$ & 22.60 & 28.16 \\
\hline 8 & $(\square ; \square ; \square)$ & $(3.3 ; 3.3 ; 3.3)$ & 22.00 & 27.67 \\
\hline 9 & $(\square ; \square ;$; ) & $(3.3 ; 3.3 ; 3.3)$ & 22.30 & 27.92 \\
\hline
\end{tabular}

*total amount of $10 \mathrm{~g}$ of substrate for EMD 1 and total concentration of $10 \mathrm{~g} / \mathrm{L}$ for EMD 2 ${ }^{* *} x_{1}$ grapefruit rind, $x_{2}$ rice bran, $x_{3}$ wheat bran for EMD 1 and $x_{1}$ naringin, $x_{2}$ rutin, $x_{3}$ hesperidin for EMD 2

Table 2. Quantitative HPLC analysis for quantification of sugars, citric acid and flavonoids. 


\begin{tabular}{lccc}
\hline $\begin{array}{l}\text { Compound } \\
(\mathrm{mg} / \mathrm{g} \text { of dry substrate) }\end{array}$ & Grapefruit rind & Rice bran & Wheat bran \\
\hline Glucose & $625.299 \pm 4.202$ & $64.126 \pm 8.741$ & $12.173 \pm 0.565$ \\
Sucrose & $4.273 \pm 0.046$ & $0.275 \pm 0.033$ & $0.267 \pm 0.021$ \\
Xylose & $\mathrm{ND}$ & $45.039 \pm 4.504$ & $\mathrm{ND}$ \\
Raffinose & $\mathrm{ND}$ & $*$ & $*$ \\
Citric acid & $305.55 \pm 0.172$ & $\mathrm{ND}$ & $\mathrm{ND}$ \\
Naringin & $8.884 \pm 0.464$ & $\mathrm{ND}$ & $\mathrm{ND}$ \\
Rutin & $5.503 \pm 0.65$ & $\mathrm{ND}$ & $\mathrm{ND}$ \\
\hline
\end{tabular}

All procedures were performed in triplicate. Mean values ( \pm standard deviation)

$N D=$ Not detected

*Values below the limit of the method

Table 3. Quantitative HPLC analysis for quantification of flavonoids in tests of EMD 2 (Table 1). 


\begin{tabular}{lccc}
\hline Run number & $\begin{array}{c}\text { Original mixture } \\
\left(\mathrm{x}_{1} ; \mathrm{x}_{2} ; \mathrm{x}_{3}\right)^{* *}\end{array}$ & Rutin $(\mathrm{mg} / \mathrm{mL})$ & Quercetin $(\mathrm{mg} / \mathrm{mL})$ \\
\hline Control 4 & $(5.0 ; 5.0 ; 0)$ & $4.071 \pm 0.784$ & $\mathrm{ND}$ \\
Control 5 & $(5.0 ; 0 ; 5.0)$ & $2.435 \pm 0.422$ & $\mathrm{ND}$ \\
Control 6 & $(0 ; 5.0 ; 5.0)$ & $5.080 \pm 1.427$ & $\mathrm{ND}$ \\
Control 7 & $(3.3 ; 3.3 ; 3.3)$ & $2.499 \pm 0.472$ & $\mathrm{ND}$ \\
Run 4 & $(5.0 ; 5.0 ; 0)$ & $*$ & $1.873 \pm 4.950$ \\
Run 5 & $(5.0 ; 0 ; 5.0)$ & $*$ & $1.578 \pm 10.382$ \\
Run 6 & $(0 ; 5.0 ; 5.0)$ & $*$ & $2.634 \pm 0.017$ \\
Run 7 & $(3.3 ; 3.3 ; 3.3)$ & $*$ & $1.905 \pm 1.208$ \\
\hline
\end{tabular}

All procedures were performed in triplicate. Mean values ( \pm standard deviation) $N D=$ Not detected

${ }^{* *} x_{1}$ naringin, $x_{2}$ rutin and $x_{3}$ hesperidin

*Values below the limit of the method

\section{Figures}




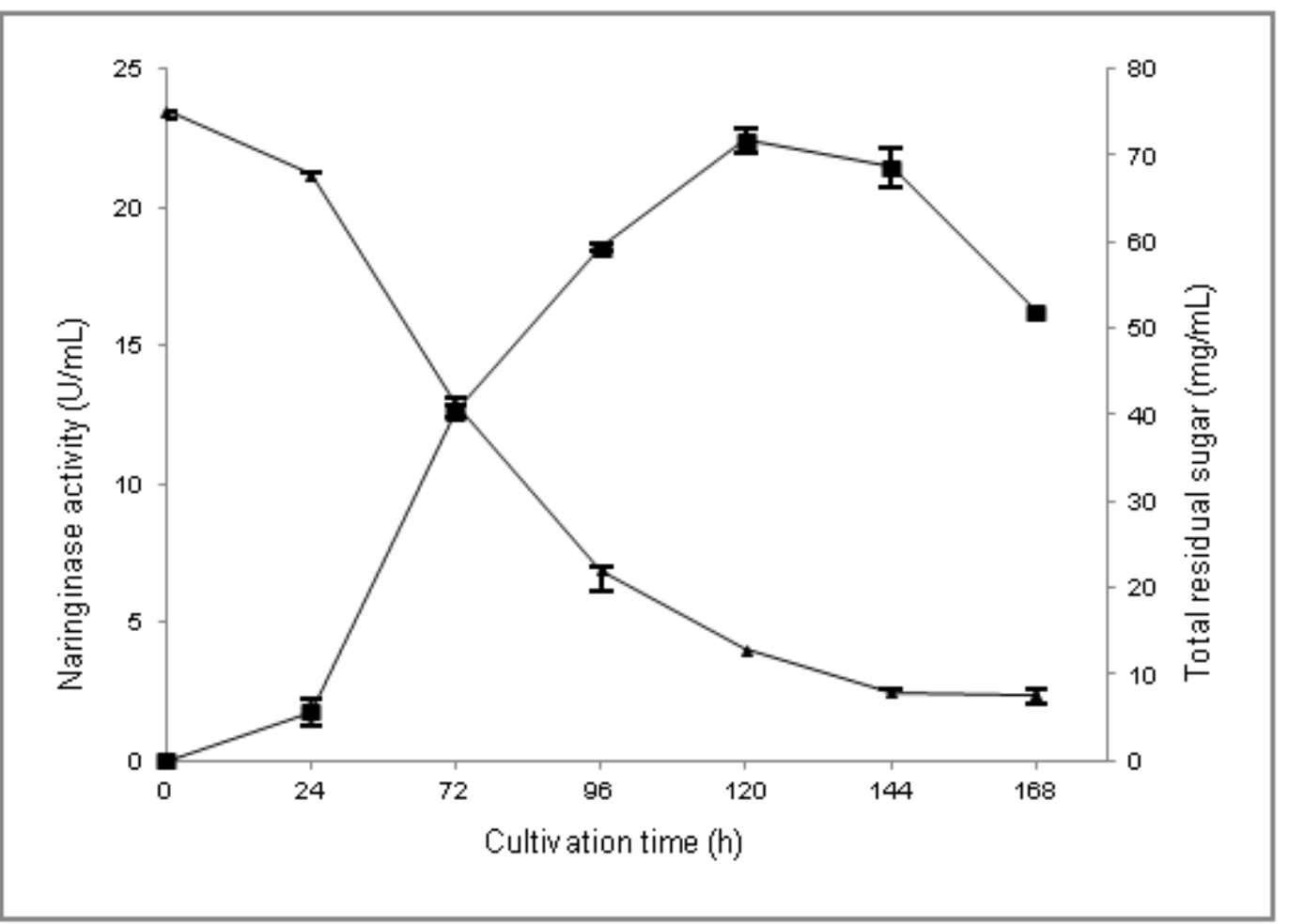

\section{Figure 1}

Kinetics of the central point of EMD 1 for naringinase production by $\mathrm{A}$. niger at $28{ }^{\circ} \mathrm{C}, \mathrm{pH} 4.5$ and naringin $(10 \mathrm{~g} / \mathrm{L})$ as inducer. Each data point represents the mean of triplicate determinations \pm SD. 
(a)

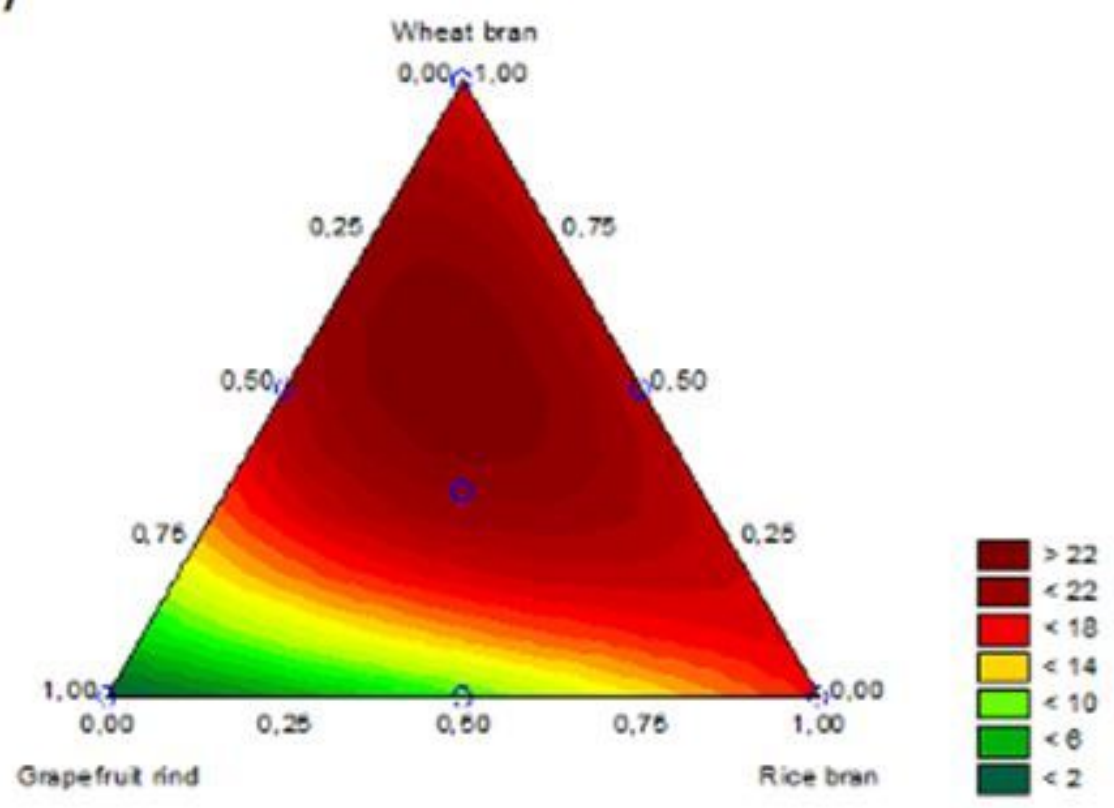

(b)

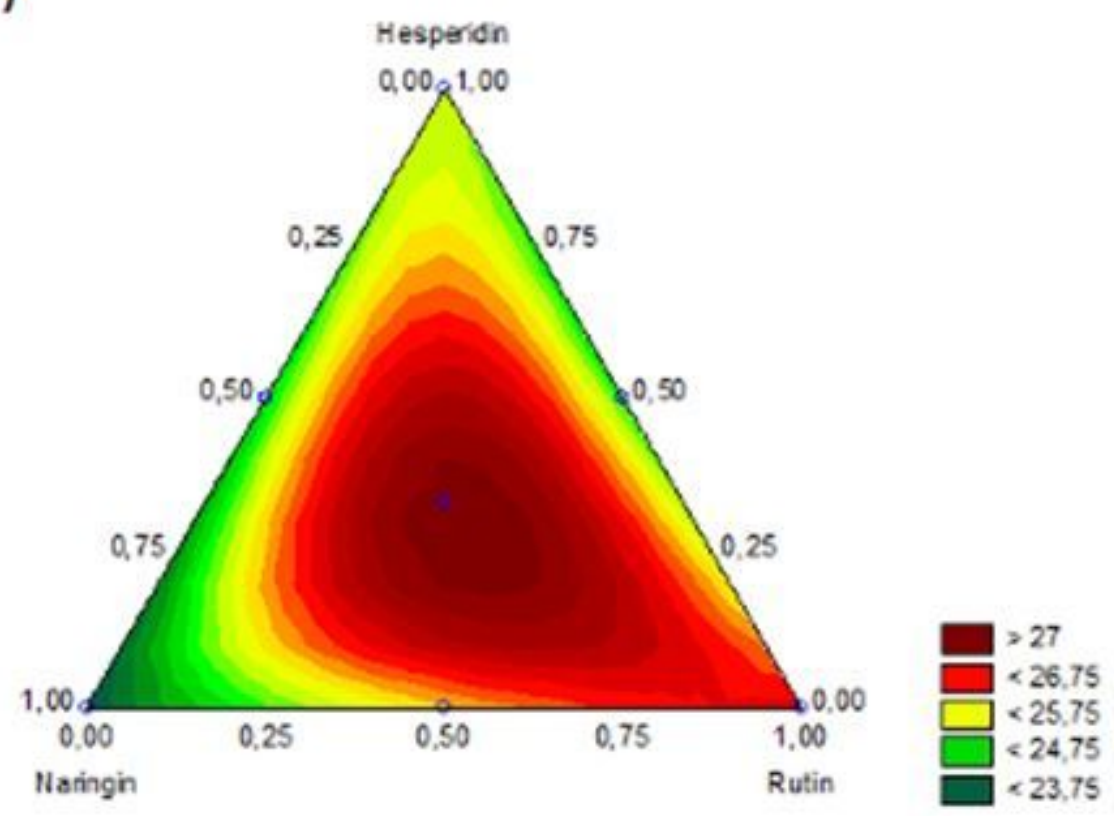

Figure 2

Contour plots of naringinase responses for A. niger cultivation using the culture medium components, (a): (10 g) grapefruit rind, rice bran and wheat bran; and (b): $(10 \mathrm{~g} / \mathrm{L})$ naringin, rutin and hesperidin. Fermentation experiments were run using SSF for 5 days at $28^{\circ} \mathrm{C}$, with initial $\mathrm{pH} 4.5$. 


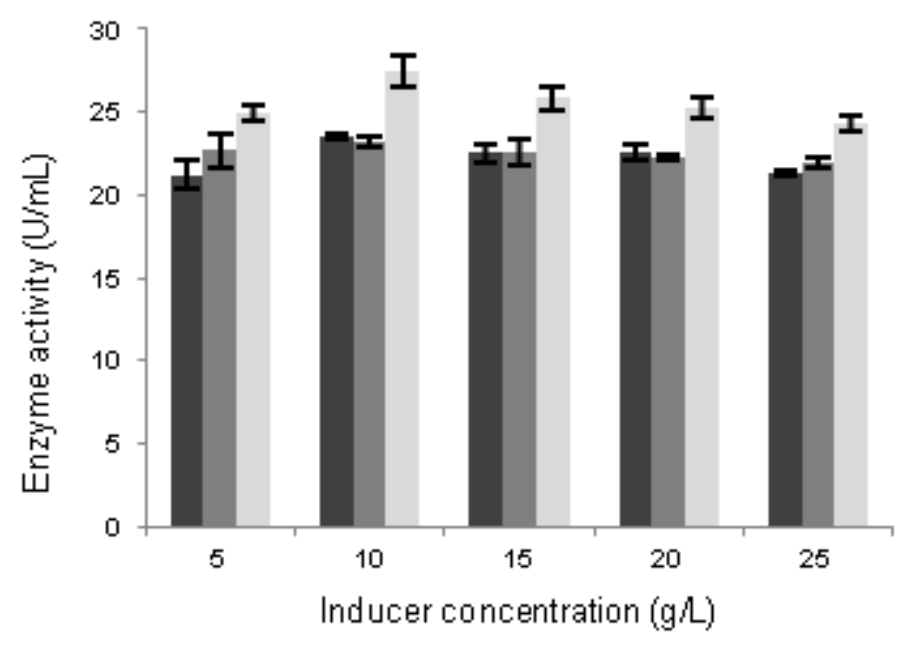

Figure 3

Effect of different inducers ( $\square$ naringin, $\square$ hesperidin and $\square$ rutin) on naringinase produced by $A$. niger 426 using SSF for 5 days at $28^{\circ} \mathrm{C}$, with initial pH 4.5. Fermentation experiments were performed based on the best condition selected from the first EMD cultivation. Each data point represents the mean of triplicate determinations \pm SD. 